\title{
Implications for practice: challenges for healthcare leaders in fostering patient safety
}

\author{
S N Weingart, D Page
}

Qual Saf Health Care 2004;13(Suppl II):ii52-ii56. doi: 10.1136/qshc.2003.009621

Although various government and regulatory organisations have identified practices that may enhance patient safety, there is little empirical or theoretical research to inform the decisions of healthcare leaders seeking to create patient safety programmes within their hospitals and clinics. In order to understand the challenges facing hospital and health system executives, we describe the experience of the Executive Session on Patient Safety. The executives identified five major problems in leading patient safety: 1) how should executives structure their organisations to deliver safe care? 2) how should executives monitor and measure their organisation's safety performance? 3) how should executives spread and sustain patient safety innovation? 4) how should executives manage the relationship with the external environment? and 5) how should executives manage their own behaviour in order to lead for safety? The organisational infrastructure needed for safer care is being developed by practitioners out in the field as a matter of necessity. Strengthening the scientific basis for organisational leadership in patient safety is a vital but neglected area of study.

See end of article for authors' affiliations

\section{Correspondence to:} Dr S N Weingart, Center for Patient Safety, DanaFarber Cancer Institute, 44 Binney Street, Boston, Massachusetts, MA 02115, USA;

saul.weingart@

dfci.harvard.edu
$\mathrm{T}$ o advance safe patient care, various prominent US hospital associations, accreditation bodies, government agencies, and an employer coalition have issued best practice recommendations for healthcare organisations to enhance patient safety. ${ }^{1-5}$

Although the efficacy and evidentiary basis of recommendations has been debated hotly, ${ }^{6} 7$ hospital and health system leaders find themselves in an environment where the content of safety programmes is dictated to some extent by external organisations and they are held accountable for meeting these mandates. And yet the mandates offer little guidance to executives about how to build the organisational infrastructure necessary to support a patient safety programme within their organisations. Government and accreditation agencies have a lot to say about what to do, but little to offer in terms of how to achieve these goals.

To date, there is little empirical or theoretical research to inform the decisions of healthcare leaders seeking to create patient safety programmes within their organisations. This reflects, in part, the difficulty of conducting rigorous study of leadership and organisational transformation. In addition, organisational science has been largely descriptive and explanatory, rather than a field that offers managers prescriptive advice about how to execute desired goals and plans. ${ }^{8}$ Lack of a research base may also reflect a bias among funding organisations and researchers to support traditional health service research rather than studies of organisational change and transformation. We tend to measure things that we know how to measure.

In order to understand the challenge of promoting safe care as seen through the eyes of hospital and health system executives, we describe here the experience of the Executive Session on Patient Safety. The Executive Session is a working group of hospital and health system executives and other stakeholders whose members agreed to work together over several years in order to understand and improve patient safety in their organisations and communities.

\section{APPROACH \\ Origins}

The Executive Session model was created at Harvard University's John F Kennedy School of Government in 1983. In contrast to prevailing models that called for dissemination of knowledge from the academy to the world of practice, the founders of the Executive Session sought to use the university as a place to convene and a setting to learn from practitioners about leadership and organisational change. ${ }^{9-12}$ The goal was to assemble a working group of prominent and thoughtful individuals who could develop powerful ideas about important social problems, test the concepts they developed in their organisations, and then report back to the group on their successes and failures. Further, members could disseminate lessons learned beyond their own organisations by virtue of their professional stature and public profile.

Early Executive Sessions dealt with problems in crime and human services. The first Executive Session in health care met from 1998 to 2000 to address medical error and patient safety. ${ }^{12}$ The members set out to understand why the problem of medical error, which had been well documented in the scientific literature, had not yet been widely recognised as a problem among healthcare leaders.

With the release of the 1999 Institute of Medicine report on patient safety, the Executive Session entered a new phase. Harvard Medical Error Executive Session Alumnus and Allina Healthcare System Executive Officer Gordon Sprenger urged officials at $3 \mathrm{M}$ Corporation, the 
National Patient Safety Foundation, Harvard, the Minnesota Health and Hospital Partnership, and local hospital and health system leaders to bring the Harvard model to the state of Minnesota ( 5 million population). With funding and support from Eli Lilly, Aventis, GlaxoSmithKline, Pfizer, $3 \mathrm{M}$, and the University of Minnesota, the members of the session have met in an intensive retreat twice yearly since 2001 with the explicit goal of improving the health and safety of the citizens of Minnesota.

\section{Participants}

The members of the Minnesota Executive Session on Patient Safety were selected by a planning group that included practitioners and academics. The Minnesota group comprised 30 members; one third had executive or governance responsibility for a hospital or health system. The remaining members included other stakeholders such as representatives from insurers, hospital associations, employers, state government, and the university, as shown in box 1 .

\section{Design}

The format of the Executive Session is described elsewhere. ${ }^{10-12}$ Briefly, members received briefings about new developments in patient safety policy. They reviewed case studies of leadership innovation and examined specific topics that the members themselves identified. A substantial part of each meeting was devoted to receiving members' reports about patient safety initiatives in their own organisations, including obstacles encountered and lessons learned. At the end of each meeting, the group identified points of agreement and discord and topics that required examination in subsequent meetings. In this way, the group set its own agenda based on issues that the group regarded as problematic and worthy of further study and discourse.

\section{Box 1 Minnesota Executive Session on Patient Safety}

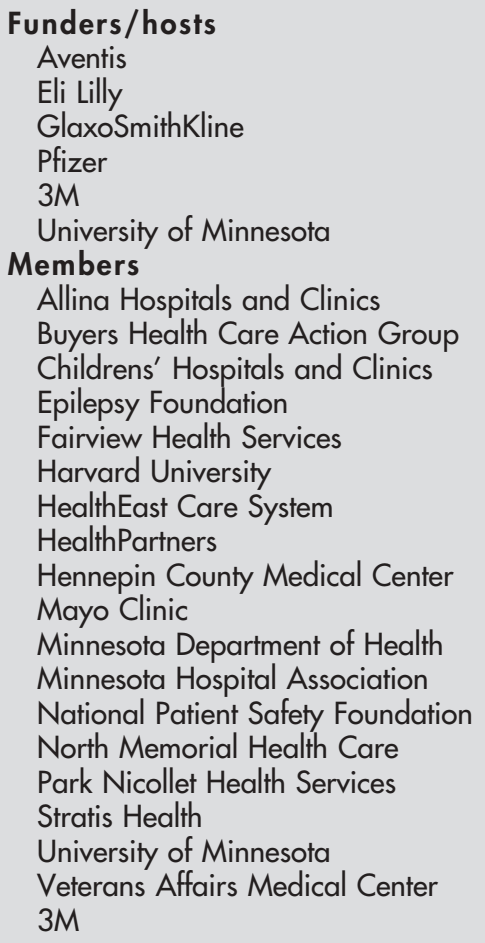

\section{Data analysis}

To characterise the challenges facing executives in building a patient safety programme, we reviewed data from several sources. We examined a summary document from the original Harvard Executive Session on Medical Error and Patient Safety..$^{13}$ We reviewed case studies of patient safety innovation at healthcare delivery systems in Minnesota, Massachusetts, and the federal Veterans Administration-all Executive Session member organisations. ${ }^{14-18}$ We drew most heavily from the Minnesota Executive Session on Patient Safety, now in its fourth year of deliberations. At the end of each two day meeting, a facilitator prepared a summary of key points of consensus and debate for open discussion and revision by the group as a whole. Minutes were written and disseminated to participants in advance of each meeting and summarised at the beginning of each meeting. These topics were integrated into the agenda of subsequent meetings. As the work proceeded, the group continued to summarise and synthesise its conclusions. The findings below were ultimately reviewed by the entire membership in April 2003. A written summary was reviewed by the planning committee and submitted on behalf of the Executive Session to the 2nd National Summit on Patient Safety Research, Washington DC, 7 November 2003.

\section{FINDINGS}

Box 2 shows the five major problems that health executives and their colleagues identified in leading patient safety. We review each topic in turn.

\section{Organising care}

Executives believed that the organisation of the hospital and clinic contribute importantly to the level of patient safety. There needs to be an infrastructure to support patient safety goals, including electronic systems, management structures, and a culture that fosters safety. In one participant's phrase, a trickle down of expectations and infrastructure support gives rise to a bubble up of energy and innovation by frontline workers. Members were particularly interested in the contributions of governance bodies and the role of a designated change agent.

In terms of governance, American hospital and health system boards are often comprised of knowledgeable lay people who have little familiarity with concepts from fields such as human factors engineering, for example, that are germane to patient safety. However, board members have valuable roles to play by setting the management team's goals, reviewing and monitoring operational performance, committing financial resources to the effort, setting incentive compensation, and expressing their personal interest in the activities of frontline workers. Executive Session members developed and tested a set of governance best practices in patient safety, such as the creation of a board committee with explicit responsibility for patient safety, the development of board level safety reports, introduction of educational activities for board members, and participation of board members in executive walk rounds.

Executives were also interested in industrial models of change agency as exemplified in Six Sigma programmes at $3 \mathrm{M}$ Corporation and General Electric. They examined the role of designated change agents such as a patient safety officer for promoting patient safety. ${ }^{19}$ Members focused on several features of the role, as shown in box 3. Change agents in different organisations had responsibilities that included safety education, error reporting, analysis of adverse events, oversight of improvement projects, liaison with management and governance bodies, and monitoring of community and national safety efforts. No single job description or title was 
Box 2 Challenges in patient safety leadership

1. Organising care

- What goals should executives set with respect to patient safety?

- What management and governance structures are useful and what responsibilities should be laid out and assigned explicitly, in order to move a patient safety programme forward?

- Should quality and safety remain distinct organisational entities or would the combination offer economies of scale?

- What is a safety culture and how can health executives create one?

- What are the implications of patient safety strategy for human resources development of the healthcare workforce?

- How can we align incentives within an organisation to improve patient safety?

- How can we engage staff over whom we have little direct control?

2. Monitoring and measuring safety

- How should we monitor our progress in achieving safety milestones?

- What metrics are most useful?

3. Spreading and sustaining change

- How can leaders nurture, disseminate, and maintain successful innovation, particularly when faced with competing priorities?

- How should leaders choose among best practice recommendations and potentially expensive investments in technology?

4. Public reporting and accountability

- What can a leader promise consumers about their next episode of care?

- What kinds of events are they obliged to report to regulators?

- What should be reported publicly in order to satisfy the executive's obligation to consumers, employees, and the public good?

5. Self-management

- How can the executive communicate the safety mission in a way that is taken seriously? What arguments and behaviours make the case?

endorsed because different models may suit different organisations

Many questions remain about the organisation of safety programmes. For example, should responsibility for safety be distinct from quality improvement? How large a staff is needed? How can one align incentives within an organisation to improve patient safety? How can executives engage the medical staff?

\section{Monitoring and measurement}

Because there is no readily agreed metric for assessing safety, it is difficult for leaders to evaluate the care their
Box 3 Characteristics of the patient safety

change agent

- The change agent should be a clinician (especially a practicing physician), as this can build credibility with colleagues.

- Ideally, the change agent is an individual with tenure in the organisation.

- The change agent must be trained in methods of quality improvement and knowledgeable about patient safety science.

- There must be direct access to the chief executive officer and ongoing support for the work.

- The change agents needs protected time (50-80\%) with staff resources.

- Initially, keeping the safety programme separate from the organisation's quality improvement programme may help to focus the safety mission and programme.

organisations provide. Incident reporting is a potentially valuable source of data about errors and injuries, but it is difficult to interpret reporting rates. High rates may reflect the presence of a culture that is non-punitive and receptive to improvement rather than an unsafe environment. ${ }^{20-22}$

Executives used various measures to assess safety, including incident reports, infection rates, pharmacist interventions, procedure related complications, and readmissions. There was no agreement on a single, universal measure and a general consensus that none would be identified. As an interim measure, executives recommended tracking the implementation of safe practices.

Several techniques hold promise for measuring and monitoring safety, such as prospective audits of high risk processes. In this approach, leaders monitor processes for deficiencies that could lead to harm. Analyses usually focus on settings where the volume is large (for example emergency departments), the hazard is high (for example in chemotherapy and surgery), or the patient is vulnerable (for example in newborns).

\section{Spreading and sustaining change}

Among the most difficult challenges for healthcare leaders is to spread improvements. The professional silos within healthcare organisations are deep. Barriers to the spread of innovation are rooted in the professional cultures of healthcare providers, in the geographic isolation of wards and units, and by the paucity of institutional mechanisms for sharing lessons learned and driving change. Leaders find it tremendously difficult to spread a successful patient safety innovation introduced in one unit to other units in the same hospital or clinic or to other practice settings in the network or community.

Similarly, the development of an innovative programme is no guarantee that it will persist. Leadership priorities change periodically, and workers may fail to embrace a patient safety proposal until it is clear that no other initiative waits in the wings. Because organisations deal with multiple priorities, middle managers must juggle competing mandates in multiple domains, such as financial performance, bioterrorism preparedness, and information system implementation, as well as patient safety.

Making progress in these areas requires a degree of consistency, the development of incentives for managers, and integration of safety goals into the deeper cultural goals 
of the organisation. But how is this best accomplished? Specifically, how can leaders nurture, disseminate, and maintain successful innovation, particularly when faced with competing priorities? How should leaders choose among best practice recommendations and potentially expensive investments in technology? Creating a safety culture is widely heralded as a patient safety best practice, but the components of a coherent and organised programme to build a safety culture are not well characterised.

\section{External reporting and accountability}

The executives agreed that healthcare leaders are accountable to consumers as well as to regulatory and accreditation bodies for the quality and safety of care delivered in their organisations. Patient safety, because it depends critically on the integrity of systems of care, belongs both to the clinicians at the bedside and to the administrators who oversee the system as a whole.

Executives endorsed the concept that healthcare organisations should make a public commitment to patient safety. This action could contribute to the credibility of their organisations and address existing patient expectations. However, there may be a discrepancy between the types of events healthcare organisations are obliged to report to regulators under existing law and regulation and reports that would satisfy the executive's obligation to consumers, employees, and the public good. Furthermore, there is a tension between the obligation to disclose publicly sentinel events and the ability to create an environment within healthcare organisations that promotes honest disclosure and learning. The National Quality Forum's list of serious reportable events could serve as the basis for a coherent and rational set of public reports. ${ }^{4}$ This approach was championed by Minnesota Executive Session members and was ultimately embodied in the Minnesota Adverse Health Care Event Reporting Act of 2003. ${ }^{23}$

\section{Self-management}

Executives were mindful of the way that their own behaviours affected the patient safety mission in their organisations. The Minnesota group began where the original Harvard Executive Session ended, by accepting the principle that patient safety is a non-delegable responsibility of the executive. ${ }^{13}$ As the individuals with ultimate responsibility for the system of care over which they preside, chief executive officers (CEOs) embraced their own role in advancing patient safety.

Executives agreed that general management principles apply to safety leadership as well. For example, CEOs must continuously take the pulse of the organisation and its culture in order to understand how proposed programmes will be accepted and to anticipate sources of resistance. They should calibrate expectations and build trust with workers and understand the importance of individuals' enlightened self-interest. Chief executive officers should allocate time for teaching and mentoring. Many Chief executive officers advocated the use of data to make the case for change, especially with physicians, and underlined the importance of developing financial information about the impact of medical errors and cost of improvements to enhance patient safety. Chief executive officers should set explicit goals for managers with respect to safety and tie incentives to the accomplishment of these goals. Chief executive officers should evaluate and embrace best practices and technology and explore the real value added of electronic medical records.

Leadership for patient safety, however, offers challenges that go beyond the usual stuff of general hospital administration. Perhaps because health care is intended to heal, unintentional harm is a particularly troubling event for the patient, their family, and those who provide care.
Dealing with errors and accidental injuries requires that leaders deal with the injury itself and its meaning to those involved. Executives' personal involvement in these cases communicates a powerful message about the organisations' commitment to ensuring safety. During tragedies, leaders' symbolic acts are at least as important as their statements.

\section{DISCUSSION}

Research to date in patient safety has focused extensively on the epidemiology of error and injury, particularly in acute care settings. ${ }^{24-27}$ Several studies described the value of specific improvements that reduced errors at the bedside, such as pharmacist rounds with intensive care unit teams and computerised electronic order entry. ${ }^{28}{ }^{29}$ Relatively little attention has been paid to the organisation of care and its impact on safety outcomes, safety practices, and safety cultures. ${ }^{30}$ More scholarly work needs to be done to understand and inform the management of hospitals and health systems and to guide the work of executives in creating safe care.

The organisational infrastructure required for the effective practice of patient safety is being developed out in the field, without the benefit of a research base, as clinicians, quality improvement professionals, and health administrators seek to create viable and effective programmes. Increasingly, mandates by regulatory and accreditation bodies for safe practices occupy the organisation's attention. But these mandates typically prescribe safe practices at the bedside rather than the development of environments where safety may flourish.

The participants in the Patient Safety Executive Sessions represent a reflective community of healthcare leaders in search of a better art and science of organisational change. The observations of the Executive Session, however, are subject to several limitations. The members represent a small and selected group of leaders who may not represent healthcare executives in other communities. The regulatory environment in the US differs from the arrangements in Canada and Western Europe, although there is substantial interest in patient safety on both sides of the Atlantic. The Executive Session process may have created conditions that helped to facilitate innovation, improvement initiatives, and self-reflection. Nevertheless, the executives' observations have good face validity and represent a potentially fertile resource for hypothesis generation. Organisational theorists may find that the Executive Session offers a window on some of the difficult problems that health executives confront.

The model also offers a replicable format for creating an intentional community of leaders and learners. Although we have emphasised here the managerial challenges that leaders identified in the deliberations of the Executive Session, the experience of participation is potentially transformational for its members. The Executive Session created a community of practice with a common vocabulary for describing the problems they encountered, a set of shared norms and aspirations, a collective agenda, and a ready way of testing and disseminating innovations in practice. ${ }^{31}$ Active recruitment of prospective safety leaders into local working groups may cement their commitment to this work and align their efforts. It may also accelerate the pace of change by facilitating the translation of research into action and innovation into practice.

Healthcare organisations are complex adaptive systems that beguile even the most gifted manager and visionary planner. Strengthening the scientific basis for organisational leadership in patient safety is a vital but neglected area of study. 


\section{Key messages}

- Although healthcare executives are accountable to consumers and regulatory agencies for implementing patient safety mandates, little is known about how to execute these goals.

- The deliberations of the Executive Session on Patient Safety offer a window on the challenges facing US healthcare leaders in fashioning safe care.

- Health care executives identified five major problems in leading patient safety: creating effective organisational structures, monitoring and measuring performance, spreading and sustaining innovation, demonstrating accountability to consumers and overseers, and managing their own behaviour.

- Strengthening the scientific basis for organisational leadership in patient safety is a vital but neglected area of study.

\section{Authors' affiliations}

S N Weingart, Center for Patient Safety, Dana-Faber Cancer Institute, Boston, Massachusetts, USA

D Page, Fairview Health Services, Minneapolis, USA

An earlier version of this manuscript was submitted as testimony to the 2nd National Summit on Patient Safety Research, Washington DC, 7 November 2003

\section{REFERENCES}

1 Kohn LT, Corrigan JM, Donaldson MS, eds. To err is human: building a safer health system. Washington, DC: National Academy Press, 1999.

2 American Hospital Association. Prescriptions for safety. 1999. http:// www.hospitalconnect.com/aha/key_issues/medication_safety/ahainitiative/ medicalsafety20015.html (accessed 3 March 2004).

3 Joint Commission on the Accreditation of Healthcare Organizations. National Patient Safety Goals. 2004. http://www.jcaho.org/ accredited+organizations/patient+safety/index.htm (accessed 3 March 2004).

4 National Quality Forum. "Safe practices" in hospital care. 2001. http:// www.qualityforum.org/txNQFprojectsummarysafepractices.pdf (accessed 3 March 2004)

5 Leapfrog Group. Leapfrog initiatives to drive great leaps in patient safety. hitp://www.leapfroggroup.org/safetyl.htm (accessed 3 March 2004).

6 McDonald CJ, Weiner M, Hul SL. Deaths due to medical errors are exaggerated in Institute of Medicine Report [editorial]. JAMA 2000;284:93-4.

7 Leape LL. Institute of Medicine medical error figures are not exaggerated [editorial]. JAMA 2000;284:95-7.

8 Moore MH. Social science and policy analysis. In: Callahan D, Jennings B, eds. Ethics, the social sciences, and policy analysis. New York, NY: Plenum, 1983:271-91

9 Hough L. Meeting of the minds. Kennedy School Bulletin. John F Kennedy School of Government, Harvard University, Cambridge, Massachusetts, Spring 2002, 32-7. http://www.ksg.harvard.edu/ksgpress/bulletin/ spring2002/features/meeting.html (accessed 4 August 2003).
10 Moore MH, Hartmann FX. On the theory and practice of "Executive Sessions." Working paper, Program in Criminal Justice Policy and Management of the Malcolm Wiener Center for Social Policy, John F. Kennedy School of Government, Harvard University, Cambridge, Massachusetts. 1999. http://www.ksg.harvard.edu/criminaljustice/ publications/exec_sessions_theory.pdf (accessed 3 March 2004).

11 Hartmann FX, Moore MH, Gornick JC. Executive Sessions. Working paper\#89-07-01, Program in Criminal Justice Policy and Management of the Malcolm Wiener Center for Social Policy, John F. Kennedy School of Government, Harvard University, Cambridge, Massachusetts. 1999. http:// www.ksg.harvard.edu/criminaljustice/publications/executive_sessions.pdf (accessed 4 August 2003).

12 Weingart SN, Morath JM, Ley C. Learning with leaders to create safe health care: the executive session on patient safety. J Clin Outcomes Manage 2003; 10:597-601

13 Minnesota Alliance for Patient Safety. A call to action: roles and responsibilities for assuring patient safety. Minnesota Hospital Association, Minneapolis. 2002. http://www.mnpatientsafety.org/pdfs/ A\%20Call\%20to\%20Action.pdf (accessed 3 March 2004).

14 Freshman ME, Weingart SN. Reinventing quality and safety in the new VA. Case study prepared for the Harvard Executive Session on Medical Error and Patient Safety. Cambridge, MA, 2002.

15 Weingart SN, Freshman ME. Creating a safety culture in the new VA. Case study prepared for the Harvard Executive Session on Medical Error and Patient Safety. Cambridge, MA, 2002.

16 Weingart SN, Sharma S, Kim H. A quiet revolution: patient safety at Mayo Clinic Rochester. Case study prepared for the Harvard Executive Session on Medical Error and Patient Safety. Cambridge, MA, 2002.

17 Weingart SN, Blum L, Balik B, et al. Creating a patient safety program at Allina Hospitals and Clinics. Case study prepared for the Harvard Executive Session on Medical Error and Patient Safety. Cambridge, MA, 2003.

18 Weingart SN. Making medication safety a strategic organizational priority. Jt Comm J Qual Improv 2000;26:341-8.

19 Rozich JD, Resar RK. Medication safety: one organization's approach to the challenge. J Clin Outcomes Manage 2001;10:27-34

20 Edmondson AC. Learning from mistakes is easier said than done: group and organizational influences on the detection and correction of human error. J Appl Behav Sci 1996;32:5-28.

21 Edmondson AC. Psychological safety and learning behavior in work teams. Adm Sci Q 1999;44:350-83.

22 Edmondson AC. The local and variegated natures of learning in organizations. Organization Science 2002;13:128-46.

23 Minnesota Adverse Health Care Events Reporting Act of 2003. http:// www.revisor.leg.state.mn.us/slaws/2003/c099.html (accessed 3 March 2004).

24 Brennan TA, Leape LL, Laird NM, et al. Incidence of adverse events and negligence in hospitalized patients. N Engl J Med 1991;324:370-6.

25 Wilson RM, Runciman WB, Gibberd RW, et al. The Quality in Australian Health Care Study. Med J Aust 1995;163:458-71.

26 Bates DW, Cullen DJ, Laird N, et al. Incidence of adverse drug events and potential adverse drug events. JAMA 1995;274:29-34.

27 Vincent C, Neale G, Woloshynowych M. Adverse events in British hospitals: preliminary retrospective record review. BMJ 2001;322:517-9.

28 Leape LL, Cullen DJ, Clapp MD, et al. Pharmacist participation on physician rounds and adverse drug events in the intensive care unit. JAMA 1999;282:267-70.

29 Bates DW, Leape LL, Cullen DJ, et al. Effect of computerized physician order entry and a team intervention on prevention of serious medication errors. JAMA 1998;15:1811-6.

30 Shojania KG, Duncan BW, McDonald KM, et al. Making health care safer: a critical analysis of patient safety practices. US Agency for Healthcare Research and Quality, Evidence Report/Technology Assessment, No. 43. Rockville, MD: Agency for Healthcare Research and Quality, 2001:575-78.

31 Seeley Brown J, Duguiod P. Organizational learning and communities of practice: toward a unified view of working, learning, and innovation. Org Sci $1991 ; 2: 40-58$. 